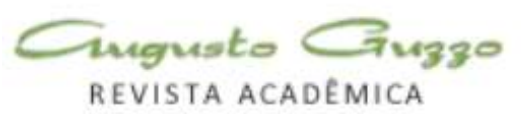

\title{
Estudo Da Instalação De Transmissores De Pressão No Esterilizador De Um Sistema UHT (Temperatura Ultra Rápida)
}

\author{
Pressure Transmitters Installation Of Study In The Sterilizer A UHT \\ System (Ultrafast Temperature)
}

Eliédina Nunes dos Santos ${ }^{1}$, Leandro Ventura Fernandes², Luciano Galdino ${ }^{3}$

\begin{abstract}
1.Graduada em Mecatrônica Industrial e graduanda em Engenharia Mecatrônica pela faculdade Eniac. E-mail: edinhanunes@yahoo.com.br. 2.Graduando em Engenharia Mecatrônica na faculdade Eniac. E-mail: leandroventura000@gmail.com

3.Professor de Física e Elementos de Máquina na Faculdade ENIAC. Mestre em Ciências Exatas e da Terra na área de Física Nuclear pela USP, especializado em Física pela USP e Licenciado em Matemática pela UNG. E-mail: lucianogaldino1@yahoo.com.br.
\end{abstract}

\section{Resumo}

O artigo em questão apresenta um estudo realizado sobre a instalação de transmissores de pressão e análise de todos os componentes que compõe o equipamento de esterilização do sistema UHT (Temperatura Ultra Rápida), bem como suas respectivas explicações e funções. A princípio, foi exposto o estudo da instalação dos transmissores de pressão dentro desse processo industrial que atua diretamente no combate a microrganismos que não fazem bem a vida humana, exercendo um trabalho eficaz e de extrema importância. Posteriormente, foi identificado o ponto de instalação adequado e a funcionalidade desse tipo de aplicação ressaltando os focos principais de todos os equipamentos e serviços vinculados ao processo. Falando-se de maneira mais simplificada, o resultado do trabalho consiste em fazer uma monitoração em tempo real através de sensores e transmissores que funcionam como nossos olhos e o CLP que funciona como nosso cérebro.

Palavras-chaves: Transmissores. Sensores. UHT.

\begin{abstract}
The article in question presents a study on the installation of pressure transmitters and analysis of all components that make up the equipment sterilization of UHT (Ultra Rapid Temperature) system as well as explanations and their respective functions. At first, the study of the installation of pressure transmitters has been exposed within this industrial process that workes directly in combating microorganisms that are not good buman life, exerting an effective and extremely important work. Subsequently, the appropriate point of installation and functionality of this type of application has been identified highlighting the main focus of all equipment and services related to the process. Speaking in a more simplified manner, the result of the work is making a real-time monitoring through sensors and transmitters that act as our eyes and CLP that works like your brain.
\end{abstract}

Key words: Transmitters, Sensors, UHT. 


\section{Introdução}

O projeto apresentado será executado numa planta de processamento de alimentos líquidos (achocolatados), que utiliza o tratamento térmico do tipo esterilização UHT para a conservação dos alimentos. A planta é composta por homogeneizador, esterilizador (trocador de calor) e demais equipamentos que compõe a automação do processo . Ressaltando que a melhoria será realizada no esterilizador. De acordo com o tema em questão pode-se enfatizar como principal objetivo do desenvolvimento deste trabalho a melhoria na implantação de recursos tecnológicos no sistema denominado UHT (Ultra High Temperature) ou (Temperatura Ultra Rápida). O sistema UHT é um tipo de tratamento térmico por meio da esterilização. A melhoria no esterilizador consiste na implantação de transmissores de pressão, que tem como finalidade fazer o monitoramento da pressão do produto que por sua vez tem a necessidade de ser maior que a pressão da água no trocador de calor de feixe tubular do tipo indireto. $\mathrm{Na}$ medida em que esta pressão for identificada menor que a exigida pelo funcionamento normal do sistema (aproximadamente 0,3 bar), ocorrerá uma falha no sistema ocasionando a parada total da planta. A construção do esterilizador é feita por feixes tubulares revestido por um tubo onde o produto passa na parte interna do feixe tubular e a água na parte externa e em prol desta ação é necessário a instalação de transmissores de pressão, tanto no tubo do produto como no tubo da água para que assim ocorra o diferencial de pressão para o controle da planta. Todo processo é monitorado por um supervisório e o supervisório do projeto em questão utiliza-se do software In Touch e será necessário a mudança da animação do desenho da planta para implantação dos campos de leitura dos transmissores de pressão. Também será inserido no programa de CLP (controlador lógico programável) da Allen Bradley software SLC 500 que controla automação da planta, uma lógica para leitura dos transmissores cuja condição é que quando ocorrer uma falha no diferencial de pressão ocorra a parada total da planta. O projeto tem por finalidade criar um PCC (Pontos Crítico de Controle) que atende ao APPCC (Análise de Perigos e Pontos Críticos de Controle). Para justificar essa questão vale a pena ressaltar que para a segurança alimentar e a qualidade do produto ser atendida é preciso que a pressão do produto seja sempre superior a pressão da água, tendo em vista que quando ocorrer um furo na tubulação do produto por causa da fadiga (desgaste) do material a tendência seja a evacuação do produto e não a infiltração da água causando a contaminação. Na realização desse projeto foram 
utilizadas e analisadas várias fontes de pesquisa que serviram como ponto de apoio para o desenvolvimento geral do trabalho, e conforme (BARROS,2007) a nbbmetodologia, quando aplicada examina e avalia os métodos e as técnicas de pesquisa, bem como a geração ou verificação de novos métodos que conduzam à captação e ao processamento de informações com vistas à resolução de problemas de investigação.

\section{Processamento Térmico}

Em meados do ano de 1810 através do confeiteiro francês Nicholas Appert (1750-1841), surgiu a história da eliminação dos microrganismos nos alimentos, que colocou alimentos em garrafas de vidro, tampou-as com rolha e aqueceu-as em água fervente. A maioria dos alimentos assim tratados nao se deteriorou e, ele então anunciou este feito. Naquela época a microbiologia era desconhecida e Appert foi incapaz de explicar por que seu método era eficaz. Ele acreditava que com a combinação do calor e a remição do ar prevenia a tendência da decomposição dos alimentos. Nos dias atuais, o processamento térmico ainda continua sendo um dos métodos mais utilizados no processamento de alimentos. Isso porque se tem a necessidade de conservar os alimentos através da destruição de enzimas, microorganismos, insetos e parasitas, bem como adquirir os efeitos desejáveis na qualidade sensorial. Muitos alimentos são consumidos cozidos, e no caso dos alimentos assados, estes ganham sabores que não podem ser gerados de outra forma. Mediante a questão de segurança alimentar, existem duas maneiras para se fazer o tratamento térmico, uma denominada pasteurização que faz fundamentalmente a higienização, e a outra esterilização que faz a destruição de todos os microorganismos e seus esporos viáveis, e que podem causar doenças ao homem. Para isso utilizam-se técnicas apropriadas por meio da aplicação de temperaturas superiores a $100^{\circ} \mathrm{C}$. è realizada a destruição dos microrganismos presentes, esporulados ou não, mas pelo menos todos aqueles que possam multiplicar-se no produto final. Conforme (FELLOWS, 2006) o tempo necessário para esterilizar um alimento é influenciado, pela resistência do calor dos microrganismos ou enzimas que podem estar presentes no alimento, pelas condições do aquecimento, pelo $\mathrm{pH}$ do alimento, pelo tamanho do recipiente e pelo estado físico do alimento

\section{Sistema UHT}

\section{UHT (Ultra High Temperature) ou} (Temperatura Ultra Rápida) é uma técnica para a preservação de alimentos líquidos por meio da sua exposição ao calor intenso por um rápido período de tempo, destruindo os microrganismos do produto. Isto só se aplica se o produto permanecer em condições assépticas, sendo necessário evitar a 
recontaminação por meio do envase asséptico, após o tratamento térmico, em materiais de embalagem previamente esterilizados. Qualquer armazenagem do produto entre o tratamento térmico e o envase asséptico deve ocorrer sob condições também assépticas. O sistema UHT possui uma série de vantagens incomparáveis, tanto econômicas como práticas, tanto para produtores como para os retalhistas e consumidores, isso graças ao longo prazo de validade sem refrigeração. Além disso apresenta vantagens ambientais e na economia de custos em termos de distribuição à temperatura ambiente. Os produtos UHT em embalagens assépticas de cartão estão disponíveis em toda a parte e são fáceis e praticos de utilizar. A embalagem protege o produto e mantém o seu valor nutricional. $\mathrm{O}$ sistema UHT funciona de modo a termos a certeza que os esporos bacterianos não crescem no interior de um produto, tornando-o um perigo para a saúde. Nesse processo o produto é aquecido por alguns segundos e depois é arrefecido rapidamente. O produto fica então esterilizado e o sabor original se mantém preservado sem a utilização de conservantes. As temperaturas e duração necessárias dependem do produto. Se o produto for envasado em condições esterilizadas, numa embalagem esterilizada, a qual é selada para que se proteja o conteúdo, então o resultado é um produto asséptico. De acordo com (ORDÓÑEZ, 2005) é um processo que pretende destruir os microrganismos mais termorresistentes para conseguir a esterilidade comercial do produto. A figura 1 apresenta de maneira simplificada um sistema UHT. 
Figura 1. Escopo de sistema UHT.

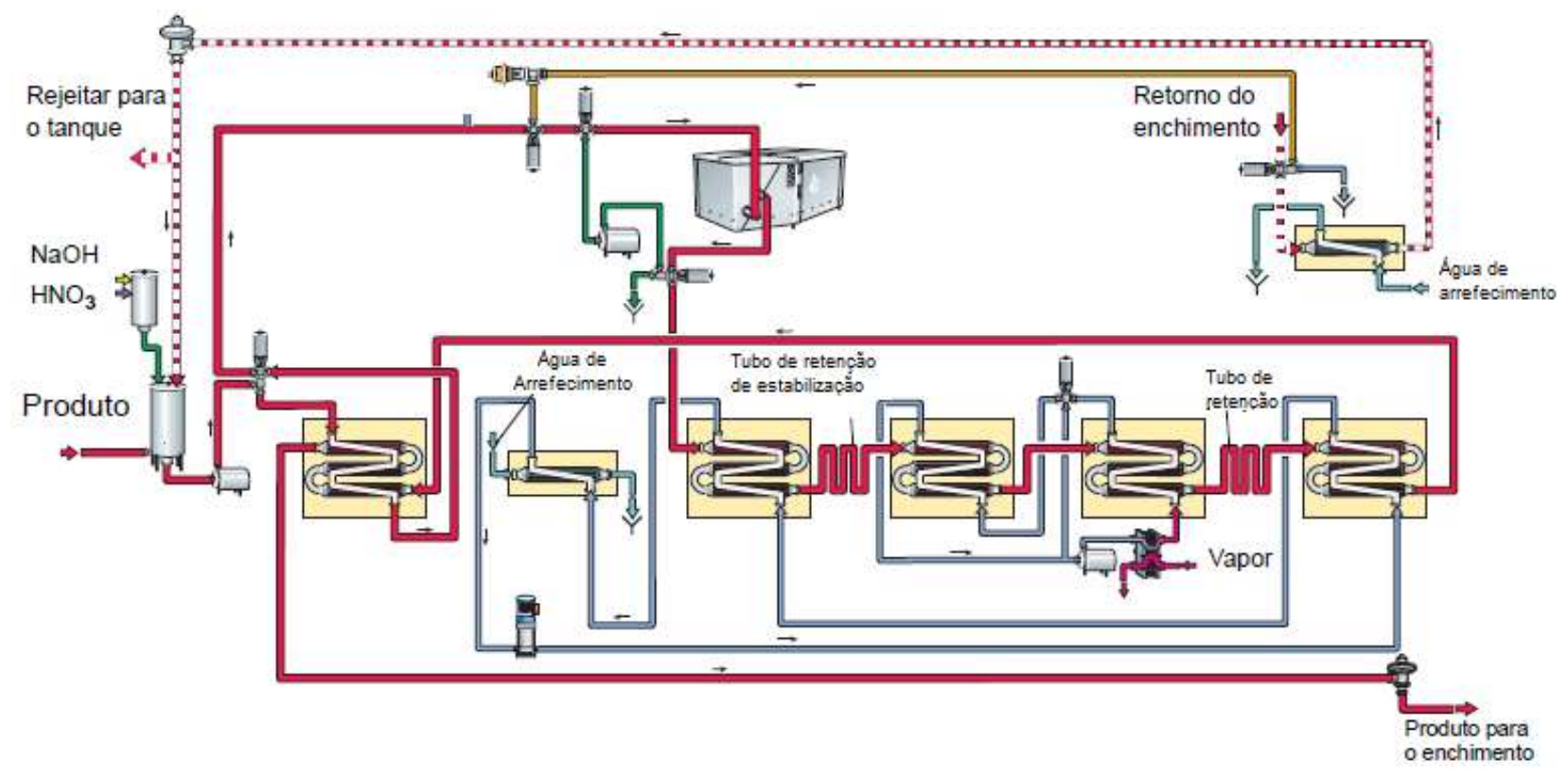

Fonte: Manual técnico tetrapak, 1996, p. 4-6.

Para se colocar uma planta de esterilização por temperatura em produção é necessário seguir vários passos. Precisa-se esterilizar a área asséptica do módulo, circulando água quente pressurizada por 30 minutos e atendendo as temperatura programadas. A parte asséptica do módulo está equipada com um circuito de esterilização interno a fim de minimizar o consumo de energia e o tempo da colocação em produção. Depois da esterilização, o módulo é arrefecido passo a passo até às temperaturas de produção. Por fim é circulada água estéril através do circuito do produto. A produção começa com o enchimento do módulo com produto através do tanque de compensação. Esse tanque de compensação é especialmente desenhado para minimizar a quantidade de produtos misturados. Quando a máquina de enchimento estiver pronta, a produção pode começar. $\mathrm{O}$ produto é regenerativamente pré-aquecido no trocador de calor antes de começar a ser homogenizado num homogenizador. O aquecimento final é feito através de um circuito de água quente indireto. $\mathrm{O}$ produto é retido num tubo de retenção durante o período de tempo requerido, após este tempo o produto é resfriado imediatamente estando pronto para ser envasado. Há dois tipos principais de sistemas UHT no mercado. No sistema direto, o produto entra em contato direto com o meio de aquecimento, seguido de um resfriamento 
instantâneo em câmara de vácuo e, eventualmente, o resfriamento adicional indireto até atingir a temperatura de envase. $\mathrm{O}$ sistema direto é dividido em sistema de injeção de vapor (vapor injetado no produto) e sistema de infusão de vapor (o produto é introduzido numa câmara de vapor). No sistema indireto, o calor é transferido de um meio de aquecimento para o produto por meio de uma parede divisória. O sistema indireto pode ser baseado em trocadores de calor a placas, tubulares ou com superfície raspada. Além disso, é possível combinar os trocadores de calor no processo indireto, de acordo com as exigências do produto e do processo. Segundo (FELLOWS, 2006) a vida de prateleira de alimentos esterilizados depende, em parte, da habilidade do recipiente de isolar por completo o alimento do ambiente. Os quatro principais tipos de embalagens passíveis de sofrer esterilização pelo calor são:
a. Latas metálicas
b. Potes ou garrafas de vidro
c. Pouches flexíveis
d. Bandejas rígidas

\section{Segurança Alimentar}

A segurança alimentar é uma questão que consiste em uma série de normas de produção, transporte e armazenamento de alimentos. Tendo em vista algumas características físico-químicas, microbiológicas e sensoriais padronizadas, segundo as quais os alimentos seriam adequados ao consumo. Estas regras são, até certo ponto, internacionalizadas, de modo que as relações entre os povos possam atender as necessidades comerciais e sanitárias.

E de acordo com Fellows (2006, p. 67)

Uma abordagem mais proativa e preventiva em segurança
alimentar e gerenciamento da qualidade, denominada
"Garantia da qualidade", foi desenvolvida durante a
década de 1980, baseado nos princípios de boas Práticas
de Fabricação (BPF) (Anom.,1998). Seu objetivo é
garantir que a qualidade e a sanidade sejam mantidas ao
longo do processo e, assim, evitar a rejeição do produto e a
perda financeira.

Dentro da questão de segurança alimentar, a análise de perigos deve ser completamente feita através da identificação, avaliação e o controle ou a eliminação de perigos no processo, e conforme (FELLOWS, 2006) significa que a análise de perigos é a identificação de ingredientes, condições de armazenagem, embalagem, pontos críticos do processo e fatores humanos relevantes que possam ser potencialmente perigosos e afetar a segurança alimentar ou a qualidade do produto. 


\section{Pressão E Os Instrumentos De Pressão}

De acordo com Moran (2005, p. 276)

Como a pressão é uma característica muito importante de um fluido, não é surpresa que diversos equipamentos e técnicas sejam utilizados para sua medição. A pressão em um ponto no interior de uma massa de fluido pode ser designada ou por pressão absoluta ou por pressão manométrica. A pressão absoluta é medida em relação à pressão zero absoluta, enquanto a pressão manométriva é medida em relação à pressão atmosférica local.

Pressão também é a relação entre uma determinada força e sua área de distribuição. $\mathrm{O}$ termo pressão é utilizado em diversas áreas da ciência como uma grandeza escalar que mensura a ação de uma ou mais forças sobre um determinado espaço, podendo este ser líquido, gasoso ou mesmo sólido. Existem duas referências para fazer a medição de pressão que são: a pressão absoluta e a atmosférica, sendo que a A palavra atmosfera designa a camada gasosa que envolve o globo terrestre com uma expessura de cerca de $50 \mathrm{~km}$, a parte inferior da camada gasosa, que se encontra na superfície da terra, suporta todas as camadas superiores e exerce, ao nível do solo, uma pressão correspondente ao peso total desta coluna gasosa. Quando se utiliza a pressão atmosférica como referência, as pressões medidas são chamadas: pressões relativas, pressões manométricas e pressões positivas.
E de acordo com Moran (2005, p. 277)

Uma técnica padrão para medição da pressão envolve o uso de colunas de liquido em tubos verticais ou em tubos inclinados. Os dispositivos de medição de pressão baseados nessa técnica são denominados manômetros.

Figura 2. Manômetro.

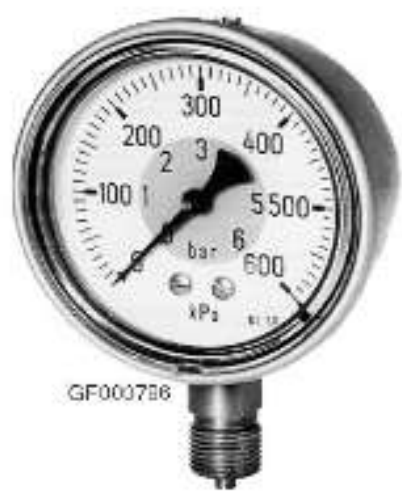

Fonte. Manual técnico tetrapak,1996, p. 2.

Todo sistema de medição de pressão é formado a princípio pelo elemento primário, o qual o mesmo estará em contato direto ou indireto ao processo, onde se tem as mudanças de pressão, e pelo elemento secundário, transmissor de pressão que terá a tarefa de traduzir esta mudança em valores mensuráveis para uso em indicação, monitoração e controle. A calibração de um transmissor de pressão envolve o ajuste de zero e span. A exatidão normalmente inclui efeitos de não-lineraridade, histerese e repetibilidade. 
Figura 3. Transmissores de pressão.

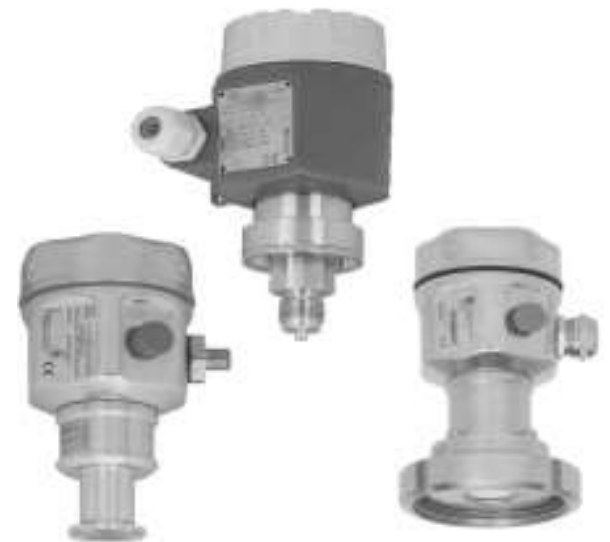

Fonte. Manual técnico tetrapak,1996, p. 3

Segundo (BEGA, 2006) os transmissores eletrônicos de pressão utilizam um elemento primário mecânico elástico, combinado com um transdutor elétrico, que gera um sinal elétrico padronizado, correspondente à pressão medida. Ele ressalta que existem duas referências para medição de pressão (absoluta e atmosférica).

É necessário periodicamente executar calibrações dos instrumentos de medição de um processo industrial, tendo em vista que o instrumento de medição que está sendo implantado e utilizado no sistema UHT são os transmissores de pressão, podendo ser calibrados, fazendo-se comparação com elemento mecânico de medição direta, utilizando-se teste de peso morto ou fazendo-se comparação com manômetro. A calibração do sistema em tela deve ser feita de três em três meses. No caso de calibração por compração com elemento mecânico de medição direta de pressão o instrumento que se utiliza de elemento mecânico elástico de pressão que será calibrado é conectado à tomada do elemento mecânico de medição direta de pressão, e então aplica-se a mesma pressão nos dois dispositivos e comparam-se as leituras obtidas em diferentes pontos da escala. O dispositivo de teste de peso morto utiliza como seu princípio de funcionamento a lei de Pascal, cujo enunciado afirma que "uma pressão exercida em qualquer ponto de um líquido confinado é transmitido, sem perda, em todas as direções”. O teste de peso morto tem uma válvula agulha na base do reservatório que permite que o óleo seja mantido preso dentro do aparelho. Existe um sistema de conexão para instrumentos medidores de pressão a ser calibrado. No centro do aparelho existe um pistão de medição que é simplesmente um cilindro de metal temperado e polido.

A comparação do manômetro padrão é semelhante ao teste de peso morto, a diferença que existe é que se substitue o pistão de medição por uma conexão ao qual será conectado um manômetro padrão. A seguir, gira-se o pistão manualmente, criando uma pressão no óleo resistente dentro do sistema de teste, pressurizando o instrumento a ser calibrado e o manômetro padrão, compara-se os valores indicados pelo instrumento calibrado com os indicados no manômetro padrão em diferentes pontos da escala. 


\section{Instrumentação Nos Sistemas De Controle}

Instrumentação é a ciência que aplica e desenvolve técnicas para adequação de instrumentos de medição, transmissão, indicação, registro e controle de variáveis físicas em equipamentos nos processos industriais. Nas indústrias de processos tais como siderúrgica, petroquímica, alimentícia, papel, etc.; a instrumentação é responsável pelo rendimento máximo de um processo, fazendo com que toda energia cedida, seja transformada em trabalho na elaboração do produto desejado. As principais grandezas que traduzem transferências de energia no processo são: pressão, nível, vazão, temperatura; as quais denominamos de variáveis de um processo. E segundo (FIALHO,2010) a pressão pode ser medida em termos absolutos ou diferenciais, desta forma é comum identificar três tipos de pressão:

- Pressão absoluta;

- Pressão manométrica;

- Pressão diferencial.

A instrumentação é utilizada para identificar à área de trabalho dos técnicos e engenheiros que atuam na área de processos industriais (técnicos de operação, instrumentação, engenheiros de processamento, de instrumentação e de automação), mas também pode estar ligados a várias maneiras e técnicas possíveis aplicadas aos instrumentos. Para fazer o controle de um processo industrial independentemente de qual seja o produto fabricado ou a sua área de atuação é preciso que seja feita a medição e o controle de uma série de variáveis físicas e químicas, para isso, é utilizada a instrumentação. A instrumentação é relacionada com os seguintes equipamentos: caldeira, reator químico, bomba centrífuga, coluna de destilação, forno, queimador industrial, refrigerador, aquecedor, secador, condicionador de ar, compressor, trocador de calor e torre de resfriamento. Em todos estes processos precisa-se monitorar e controlar as variáveis, tais como: pressão, nível, vazão, temperatura, condutividade, velocidade, etc, e para esta finalidade tem-se instrumentos de controle que permitem controlar estas variáveis em condições mais adequadas para o processo. Os sistemas de controle mantém a variável controlada no valor especificado, comparando o valor parametrizado com o valor real e fazendo ajustes para obter o valor especificado. De acordo com (FIALHO,2010) é de extrema importância, ao exprimir um valor de pressão, determinar se ela é absoluta, relativa ou diferencial.

E conforme Bega (2011, p.01)

Os processos industriais são variados, englobam diversos tipos de produtos e exigem controle preciso dos produtos 
gerados. Usualmente, os maiores usuários de instrumentação são as indústrias que atuam nas áreas de petróleo, química, petroquímica, alimento, cerâmica, siderúrgica, celulose papel, têxtil, geração de energia elétrica, etc. Em todos esses processos é indispensável se controlar e manter constantes as principais variaveis tais como pressão, nível, vazão, temperatura, $p H$, condutividade, velocidade, umidade, etc. Os instrumentos de medição e controle permitem manter $e$ controlar essas variáveis em condições mais adequadas/precisas do que se elas fossem controladas manualmente por um operador.

As classes dos instrumentos podem ser: Instrumentos cegos, instrumentos indicadores, instrumentos registradores, elementos primários, transmissores, conversores, controladores e elementos finais de controle.

O Intouch é um conjunto de softwares que se destina à criação de telas gráficas de interação com CLP's controladores Multiloop, Fieldbus, etc. O Intouch é um gerenciador de aplicativos, onde selecionamos diretórios das aplicações ou até mesmo criamos diretório para novas,e gera um histórico de dados para posterior verificação das variáveis da produção. E conforme (MORAES, 2012) entende-se por engenharia de software a tecnologia para analisar requisitos de informação e projetar arquivos e fluxos de dados, para programar os equipamentos digitais, assim como testar e manter os programas computacionais.

\section{Supervisório}

Todo processo é monitorado por um supervisório que segundo (MORAES, 2001) foi criado para supervisão de controle de quantidades elevadas de variáveis de entrada e saída digitais e analógicas distribuídas. Sua aplicação tem sido implementada tanto na área civil quanto na indústria. O supervisório é um software destinado a promover a interface homem máquina, proporcionando a supervisão de um processo através de telas devidamente configuradas. Possui telas que representam o processo que podem ser animadas em função das informações recebidas pelo controlador lógico programável (CLP).

E conforme Moraes (2012, p.23)

\footnotetext{
Na variedade de automação chamada de "complexidade média" os elementos fundamentais para sua realização física são os controladores programáveis.
}

Um Controlador Lógico Programável é conhecido por sua siglas CLP e pela sigla de expressão inglesa PLC (Programmable logic controller), é um computador especializado, geralmente as famílias de Controladores Lógicos Programáveis são definidas pela capacidade de processamento de um determinado numero de entradas e saídas. De acordo com (COSTA, 2011) CLP são dispositivos de lógica programável com circuitos integrados que contêm células lógicas digitais e interconexões programáveis. A idéia 
básica desses dispositivos é permitir ao projetista de circuitos digitais configurar as células lógicas e interconectá-las de tal forma, que construa um circuito digital complexo dentro de um único circuito integrado.

Controlador Lógico Programável segundo a ABNT (Associação Brasileira de Normas Técnicas), é um equipamento eletrônico digital com hardware e software compatíveis com aplicações industriais. Os CLP's estão diretamente aplicados nas áreas de controle de processos e de automação industrial. A aplicação desse equipamento está nas indústrias do tipo contínuo, produtoras de líquidos, materiais gasosos e outros produtos,e em outro caso a aplicação se dá nas áreas relacionadas com a produção em linhas de montagem, como exemplo as indústrias automobilísticas. Toda a informação dos sensores é concentrada no controlador (CLP) que, de acordo com o programa em memória, define o estado dos pontos de saída conectados a atuadores. Os CLPs têm capacidade de comunicação de dados via canais seriais. Com isso, podem ser supervisionados por computadores formando sistemas de controle integrados. A figura 4 mostra o CLP utilizado neste projeto em questão.
Figura 4. Controlador programável SLC 500
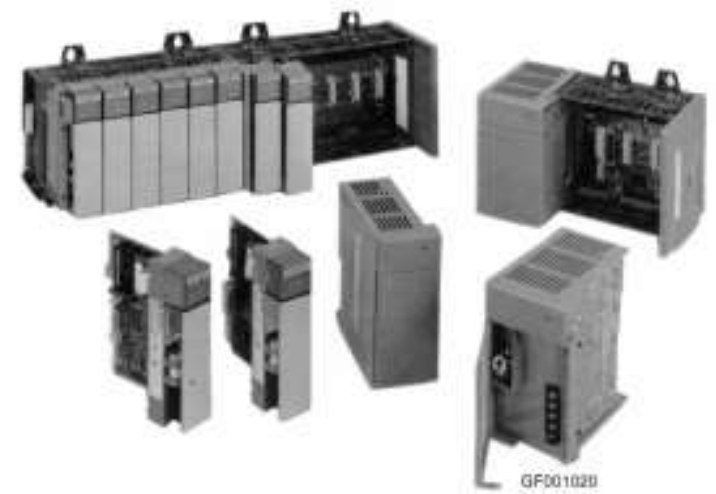

Fonte. Manual técnico tetrapak,1996, p. 10.

O SLC 500 modular é um sistema de controlador programável. Os componentes foram construídos como módulos, os quais estão montados em conjunto dentro de chassis de tamanhos fixos. O Sistema central é composto de: chassis, módulo de corrente e módulo de processador. Os módulos de E/S da série 1746 (outros tipos tais como E/S Flex podem ser usados como E/S remotas) foram incluídos para formar um sistema completo. No plano básico do chassis, estão distribuidos pelos módulos de E/S a alimentação de corrente e os sinais do processador. Os chassis podem ser ligados em conjunto, permitindo localmente haver mais módulos num sistema. Os módulos do processador e módulos especiais têm interfaces para a comunicação com outros sistemas e dispositivos. 


\section{Instalação Mecânica}

Todo trabalho da parte mecânica será feito no módulo do trocador de calor de feixe tubular mostrado a seguir na figura 5 , que tem a função de trocar calor entre o produto e a água que em determinada seção estará quente e outra seção estará gelada. Será necessário trabalho de corte e solda na tubulação do trocador em determinadas posições estratégicas que visa criar um diferencial de pressão entra a água e o produto. Será cortada a tubulação e soldado um tubo tipo " $T$ " que também estará soldado uma ponta SMS (Short Mensseger Service), ou (Serviço de Mensagem Curta) para conexão do transmissor de temperatura.

Outro trabalho que deve ser feito é a verificação da solda através de um processo chamado endoscopia que consiste na visualização da solda internamente na tubulação com o auxílio de uma câmera e quando encontrado uma anomalia na solda a mesma terá que ser refeita.

Figura 5. Trocador de calor de feixe tubular.

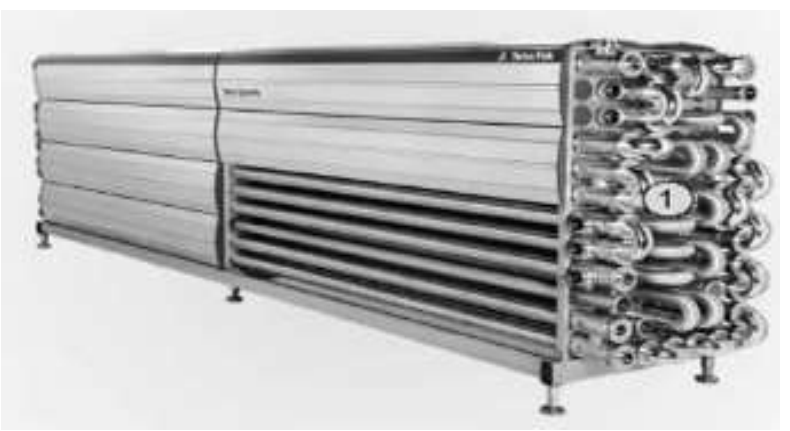

Fonte. Manual técnico tetrapak, 1996, p.12.
O primeiro passo para desenvolver a parte mecânica é a desmontagem do trocador de calor (figura 6) para facilitar o corte e a solda evitando assim retrabalho.

Figura 6. Desenho do trocador de calor com a curva desmontada.

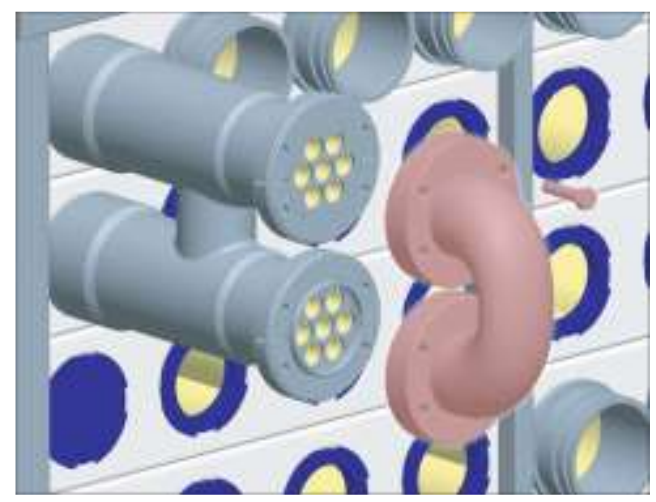

Fonte: Manual técnico tetrapak, 1996, p. 13.

\section{Instalação Elétrica}

Para cada transmissor de pressão será necessário a passagem de um cabo de instrumentação que possui uma blindagem que evita ruído na transmissão do sinal entre o amplificador do transmissor de pressão e o controlador lógico programável. Através destes cabos será feita a conexão entre a saída do transmissor e a entrada do CLP, para que o sinal seja visualizado tanto pelo programador lógico como pelo supervisório.

Será necessário, em alguns trechos da planta, a montagem de eletrocalhas para a acomodação dos cabos e para evitar a passagem destes cabos 
de instrumentação junto com cabos de motores (potência).

Também será feita a atualização do esquema elétrico com os novos instrumentos e seus respectivos símbolos para facilitar uma futura manutenção. Serão marcados também os transmissores e seus respectivos cabos através de etiquetas para que seja possível sua identificação no campo e colocado terminais nos fios para uma melhor conexão elétrica.

\section{Automação No Sistema UHT}

A automação no sistema UHT tem por finalidade fazer a interação entre as áreas elétrica, eletrônica e mecânica do processo em questão. E com a implantação da automação podemos ter uma maior produtividade e melhor controle do processo, garantindo assim a segurança alimentar nos pontos críticos de controle. Entende-se por automação qualquer sistema, apoiado em computadores que substitua o trabalho humano a favor da segurança das pessoas, da qualidade dos produtos, da rapiez da produção ou da redução de custos, assim aperfeiçoando os complexos objetivos das industrias e dos serviços. A automação envolve a implantação de sistemas interligados e assistidos por redes de comunicação, compreendendo sistemas supervisórios e interfaces homem-maquina que possam auxiliar os operadores no exercicio da supervisão e da analise dos problemas que porventura venham a ocorrer.
Segundo (FELLOWS, 2006) a automação significa que toda a ação necessária para controlar um processo a uma eficiência ideal é controlada por um sistema que opera usando instruções nele programadas.

E segundo Groover (2011, p.56),
A automação pode ser definida como a tecnologia por meio da qual um processo ou procedimento é alcançado sem a assistência bumana. É realizada utilizando-se de um programa de instruções combinado a um sistema de controle que executa as instruções. Para automatizar um processo é preciso energia não só para conduzir o processo como para operar o programa e o sistema de controle.

A área de automação no sistema UHT fará a adequação do controlador lógico e do supervisório com a inclusão dos novos instrumentos que são os transmissores de pressão. No controlador lógico será configurado entrada analógica para cada instrumento para que o sinal do transmissor possa ser tratado internamente, criando limites de máximo e mínimo valor de leitura respeitando o limite do instrumento. Também será criado um alarme para acusar uma possível falha no instrumento, impossibilitando parada na linha de produção. E o mais importante desse projeto será a inserção de uma lógica ao qual será respeitado uma diferença de pressão entre o fluxo de produto e o fluxo de água, atendendo a seguinte condição: se a pressão do fluxo de água for menor que 0,3 bar a planta deverá ir para o passo de parada. 
Quanto ao supervisório, será implementado novas animações de cada transmissor de pressão para que o operador tenha visão de cada variável do processo.

E segundo Moraes (2001, p. 14),

A automação industrial exige a realização de muitas funcões. Ela pode ser definida como a tecnologia por meio da qual um processo ou procedimento é alcançado sem a assistência humana. É realizada utilizando-se de um programa de instrucoẽes combinado a um sistema de controle que executa as instrucões. Para automatizar um processo é preciso energia não só para conduzir o processo como para operar o programa e o sistema de controle

\section{Conclusão}

São satisfatórios os resultados gerados com a aplicação dos transmissores de pressão em uma linha de produção alimentícia que utiliza o sistema de esterilização UHT, pois garante com maior eficiência o controle geral do sistema. A idéia principal deste projeto foi exatamente analisar o sistema de monitoração, e a partir disso utilizar equipamentos que possibilitam realizar essa tarefa. Como os transmissores de pressão trabalham com auxílio de outros equipamentos e juntos detectam os pontos críticos de controle, possibilitando a análise dos perigos dos pontos críticos de controle, caso ocorram falhas no sistema, o produto se manterá intacto, pois os transmissores de pressão controlam a pressão da água e do produto, mantendo diferenciais de pressão pré estabelecidos. Com esse trabalho foi possível verificar que o sistema UHT (Temperatura Ultra Rápida), o qual age diretamente no combate a microrganismos que fazem mal a vida humana, exerce um trabalho seguro e eficaz.

\section{Referências}

BARROS, Aidil Jesus da Silveira. Fundamentos de metodologia científica. $3^{\mathrm{a}}$ ed. Pearson Prentice Hall,São Paulo,2007.

BEGA, Egídio Alberto. Instrumentação Industrial. $3^{\mathrm{a}}$ ed. Interciência, Rio de Janeiro,2011.

COSTA, Cesar da. Elementos de Lógica Programável com VHDL e DSP: Teoria e Prática.1 $1^{a}$ ed. Érica São Paulo,2011.

FELLOWS, P. J. Tecnologia do processamento de Alimentos: Príncipios e Prática. $2^{\mathrm{a}}$ ed. Artmed Porto Alegre,2006

FIALHO, Arivelto Bustamante.Instrumentação Industrial: Conceitos, Aplicações e Análises. $7^{\mathrm{a}}$ ed.Érica ,São Paulo,2010.

GROOVER, Mikel. Automação Industrial e Sistemas de Manufatura/ Mikel Groover; tradução Jorge Ritter, Luciana do Amaral Teixeira, Marcos Vieira; revisão técnica José Hamilton 
Chaves Gorgulho Júnior. - $3{ }^{a}$ Ed - São Paulo : Pearson Prentice Hall, 2011.

MORAES, Cicero Couto de. Engenharia de Automação Industrial. $2^{\mathrm{a}}$ ed. LTC Rio de Janeiro,2012.

ORDÓÑEZ, Juan A. Tecnologia de Alimentos.

$1^{\mathrm{a}}$ ed. Artmed, Madrid, Espanha,2005.
MORAN, Michael J. Introdução à engenharia de sistemas térmicos: termodinâmica, mecânica dos fluidos e transferência de calor; tradução Carlos alberto Biolchini da Silva. - Rio de Janeiro: LTC, 2005. 